\title{
Modification of the human glabella reflex by antecedent acoustic stimulation
}

\author{
CHRISTOPHER L. STITT \\ Department of Industrial Relations and Organizational Behavior, Temple University \\ Philadelphia, Pennsylvania 19122 \\ and \\ HOWARD S. HOFFMAN and CAROL J. DeVIDO \\ Bryn Mawr College, Bryn Mawr, Pennsylvania 19010
}

\begin{abstract}
The eyeblink elicited by a mechanically produced tap to the glabella was inhibited by a $50-\mathrm{msec}, 80-\mathrm{dB}$ SPL tone presented in the interval 50 to $800 \mathrm{msec}$ prior to the tap, but maximal inhibition occurred when the lead interval was $100 \mathrm{msec}$. At this lead interval, the amount of inhibition was an increasing function of prestimulus intensity, but reliable inhibition was detected when prestimulus intensity was only $30 \mathrm{~dB}$ SPL. With a given inhibitory prestimulus, the amount of inhibition was independent of the intensity of the blink-eliciting tap. Monaural presentation of a prestimulus was found to produce more inhibition than the binaural presentation of that same prestimulus. The offset of an otherwise continuous binaural acoustic signal $100 \mathrm{msec}$ prior to a tap inhibited the eyeblink, but more inhibition was found when offset occurred in only one ear.
\end{abstract}

Reflex modification is a phenomenon in which the reflex elicited by one stimulus is modified by the prior presentation, withdrawal, or change of another (usually weaker) stimulus. The work reported here was designed to examine the reflex modification effects engendered when various acoustic events occur just prior to an eyeblink-eliciting tap to the glabella (the flattened region between the eyebrows). In particular, the work sought to determine if the eyeblink elicited by a tap to the glabella would be inhibited by an appropriately located prior acoustic event and, if so, to explore some of the parameters of the effect. At the outset, it seemed clear that information about reflex modification using the glabella reflex as the target reaction could have a number of practical and theoretical implications for the analysis of sensory systems in humans.

On the practical side, the use of a reflex modification procedure has the advantage of enabling one to objectively assess the behavioral impact of controlled sensory inputs without requiring the active cooperation of the subject. In the work reported here, all testing was accomplished while subjects were under instructions to merely watch colored slides of nature scenes. Moreover, the stimuli used here (relatively weak acoustic signals and reasonably mild taps to the glabella) were quite innocuous. Thus, they could readily be used to study sensory processes in

This research was supported by National lnstitute of Health Grant HD 10511. Requests for reprints should be sent to Howard S. Hoffman, Department of Psychology, Bryn Mawr College, Bryn Mawr, Pennsylvania 19010 infants and other potentially difficult-to-test subjects.

On the theoretical side, information about reflex modification is basic to the interpretation of the way in which the nervous system processes sensory input. Previous investigations of reflex modification using a variety of organisms (rats, pigeons, rabbits, and man) make it clear that reflex modification is a general process that operates across sensory modalities; an appropriate visual stimulus prior to a reflex-eliciting acoustic signal can modify the response to the latter, and vice versa (Buckland, Buckland, Jamieson, \& Ison, 1969; Ison \& Hammond, 1971; Schwartz, Hoffman, Stitt, \& Marsh, 1976; Stitt, Hoffman, Marsh, \& Schwartz, 1976). Moreover, under some circumstances, the reflex-modifying stimulus need only be at or near its threshold for detection to produce measurable effects (Reiter \& Ison, 1977), a finding that implies that the neural systems responsible for reflex modification may be engaged whenever sensory input is processed. At present, little is known about the nature of these systems or even about their functional effects. It seems clear, however, that a systematic analysis of reflex modification, especially as it is assessed in man, may provide clues to these issues or, at least, to the role of this phenomenon in the reactions to events in the sensory environment.

\section{EXPERIMENT 1}

The initial experiment in the present sequence was designed to determine if the glabella reflex could be inhibited by a prior acoustic signal and, if so, to 
explore the temporal parameters of the effect. The glabella reflex was first described by Overend in 1896 and, though subsequent investigations have examined its neural substrate (Kugelberg, 1952; Shahani, 1970; Shahani \& Young, 1972, 1973), the nature of its development (Clay \& Ramseyer, 1976; Cockburn \& Drillen, 1974; Prechtl \& Beintema, 1964), and its diagnostic significant (Bender, Maynard, \& Hastings, 1969), its susceptibility to reflex modification had not previously been determined. There was some reason to believe that inhibition would, in fact, occur, because previous investigations have shown inhibition of an airpuff-elicited eyeblink by prior visual (Ison, Note 1) or acoustic stimulation (Marsh, Hoffman, \& Stitt, 1976; Reiter \& Ison, 1977) and inhibition of an acousticelicited eyeblink by prior acoustic stimulation (Graham, 1975). Still, without direct empirical analysis, there was no way of knowing if the glabella reflex would be susceptible to reflex modification.

\section{Method}

Subjects. Sixteen (6 female, 10 male) graduate and undergraduate students from Bryn Mawr College participated in this experiment. Any potential subject whose hearing threshold (in either ear) for a $1-\mathrm{kHz}$ tone was more than $10 \mathrm{~dB}$ above the American National Standards Institute (ANSI) 1969 norm for young, audiologically normal adults was excused. This basic screening procedure was used in all subsequent studies reported in this paper.

Apparatus. The devices for delivering a controlled tap to the glabella and for monitoring the reflexive eyeblink that is elicited by the tap have been described in detail elsewhere (Marsh, Hoffman, \& Stitt, 1979). Briefly, the tap unit consisted of a miniature solenoid with a small (5-mm diameter) ball of silicone rubber securely fastened to its plunger. When the solenoid was activated, the ball was thrust forward with a force that was directly proportional to the applied voltage.

The eyeblink monitor consisted of a miniature optical device $(1 \times .5 \times .5 \mathrm{~cm})$ that contained an infrared light-emitting diode and a sensitive phototransistor pickup. The output of the eyeblink monitoring device was electronically processed and sent to a digital voltmeter with storage capability. This voltmeter recorded and held in display the largest voltage emitted during a 150 -msec period that began with the onset of the tap to the glabella. The electronically processed output of the device was also sent to a Tektronix storage oscilloscope (Type 564). During experimental sessions, the oscilloscope was continuously observed by an experimenter and trials were repeated on which a voluntary blink was seen to occur during or immediately preceding $(100 \mathrm{msec})$ the trial. All programming and timing of the tap device and the eyeblink monitoring device was accomplished with Coulbourn programming modules.

The tap and eyeblink monitoring devices were firmly attached to a lightweight band which was fitted on the subject's forehead and was held in place by an elastic band around the back of the subject's head. The headband was adjusted on the subject so that the silicone ball on the solenoid was approximately $3 \mathrm{~mm}$ away from the glabella and the eyeblink monitoring device was directly in front of the subject's left eye (approximately $5 \mathrm{~mm}$ away from the ends of the subject's eyelashes).

The tones which served as acoustic prestimuli were generated, shaped, and timed by Coulbourn programming modules and amplified by a Crown DC300 amplifier. Shallco precision attenuators permitted independent adjustment of stimuli in 2-dB steps. The acoustic prestimuli were delivered through TDH-39 earphones fitted with MX-41/AR cushions. The earphones and test stimuli were calibrated with a General Radio precision sound-level meter (Model 1561-A), fitted with a P.7 microphone and ANSI Type 1 coupler.

The research was conducted in an IAC double-wall soundtreated room having an ambient noise level below $25 \mathrm{dBA}$ (unless otherwise noted, all intensities are re .0002 dynes $/ \mathrm{cm}^{2}$ ). This chamber was suitably furnished and lighted, and was equipped with a rear-projection screen so that $35-\mathrm{mm}$ slides could be projected from the control room. A closed-circuit television camera and an intercom permitted continuous monitoring of the subject. All apparatus as described here remained constant throughout the series of five experiments reported in this paper.

Procedure. After each subject had been apprised of the nature of the research and had agreed to participate, he or she was seated in the IAC room and fitted with earphones and the headband holding the tap device and the eyeblink monitoring device. The subject's threshold for a $1-\mathrm{kHz}$ tone was then determined for each ear by the method of Carhart and Jerger (1959), this clinical technique being modified so that test tones were varied increments of $2 \mathrm{~dB}$ rather than $5 \mathrm{~dB}$. As previously noted, this initial procedure was used as a screening process to excuse subjects with more than a 10-dB hearing loss in either ear and was employed in all subsequent studies.

During the experimental session itself, two basic stimulus patterns were presented to all subjects. The first consisted of an eyeblinkeliciting tap to the glabella, produced by delivering a 50 -msec, $7-\mathrm{V} \mathrm{dc}$ pulse to the previously described tap solenoid. The second pattern consisted of the same eyeblink-eliciting stimulus presented at a period in time after the onset of a $1-\mathrm{kHz}$ acoustic prestimulus (intensity, $80 \mathrm{~dB}$; duration, $50 \mathrm{msec}$; rise-decay time, $10 \mathrm{msec}$ ). The interstimulus interval (ISI), which served as the independent variable in this study, was $50,100,200,400$, or 800 msec.

Each subject received six trials of each of the six experimental conditions (ISI $=50,100,200,400,800 \mathrm{msec}$, and no prestimulus). For half of the trials involving acoustic prestimuli, the tones were presented in the subject's left ear, and for the other half of the trials, the tones were presented in the subject's right ear. Trial conditions were presented in random order with an intertrial interval of $20 \mathrm{sec}$.

The subjects were told that they would receive tones and taps but that they need not attend to them and should relax and observe the colored slides that would be shown throughout the session. Except for a brief interval between trials when the slides were changed, they were projected continuously. Experimental sessions, including briefing and preparation of the subject, required no more than $30 \mathrm{~min}$ to complete.

\section{Results and Discussion}

Figure 1 shows the mean amplitude, averaged across subjects, of eyeblinks elicited in each of the five acoustic prestimulation conditions and in the noprestimulation condition (horizontal line crossing the curve). The means reported in the prestimulation conditions are averaged across left-ear prestimulation trials and right-ear prestimulation trials. This pooling procedure was employed because a t test for related measures revealed no significant difference between responses when prestimuli were presented in the left ear vs. the right ear $(t=-.10, d f=14, p>$ $.05)$.

A repeated-measures analysis of variance was performed on the data depicted in Figure 1. This analysis revealed that the observed temporal function was statistically significant $(F=14.40, d f=5 / 75, p<$ $.001)$. A Newman-Keuls analysis was then performed 


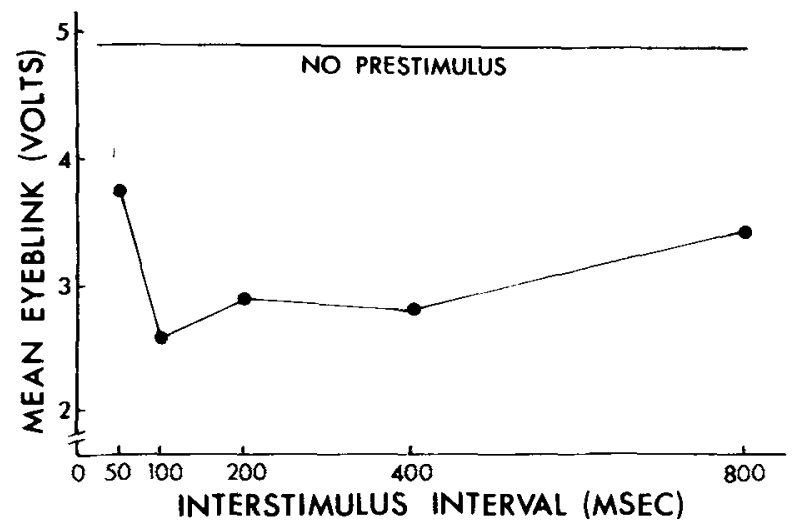

Figure 1. Mean eyeblink amplitude (across subjects) as a function of interstimulus interval. The solid horizontal line above the curve represents the mean eyeblink amplitude for the noprestimulus configuration; all other stimulus configurations employed a 1-kHz auditory prestimulus of $80 \mathrm{~dB}$ SPL.

to test the differences observed within the temporal function. This analysis indicated that the no-prestimulus condition was significantly different from each prestimulus condition ( $p<.05$ in each case). In addition, the 100 -msec ISI prestimulus condition was different from the 50-msec ISI and the 800 -msec ISI prestimulus conditions $(\mathrm{p}<.05)$. All other possible comparisons were not significant.

These results reveal that an acoustic prestimulus is effective in inhibiting the eyeblink elicited by a tap to the glabella, and that maximal inhibition is observed when the acoustic signal leads the tap to the glabella by approximately $100-400 \mathrm{msec}$. These findings closely parallel reports that inhibition of acoustically elicited eyeblink (Graham, 1975) and of airpuff-elicited eyeblink (Marsh, 1976; Reiter \& Ison, 1977) is at a maximum when the prestimulus leads the eliciting stimulus by $60-120 \mathrm{msec}$.

\section{EXPERIMENT 2}

Having established that the glabella reflex can be inhibited by an acoustic prestimulus and that the amount of inhibition is determined by the temporal interval between the prestimulus and the reflex-eliciting tap, Experiment 2 was designed to determine how the amount of inhibition varies as a function of the intensity of the prestimulus.

\section{Method}

Subjects. Eighteen (12 female, 6 male) undergraduate and graduate students from Bryn Mawr College participated in this experiment.

Procedure. All subjects were exposed to two basic stimulus patterns while viewing colored slides. One stimulus pattern consisted of an eyeblink-eiiciting tap to the glabella, produced by delivering a $50-\mathrm{msec}, 7-\mathrm{V} \mathrm{dc}$ pulse to the tap solenoid. The second pattern consisted of the same eyeblink-eliciting stimulus presented $100 \mathrm{msec}$ after the onset of a $1-\mathrm{kHz}$ acoustic prestimulus (duration,
$50 \mathrm{msec}$; rise-decay time, $10 \mathrm{msec}$ ). The intensity of prestimulus, which served as the independent variable in this study, was $30,50,70$, or $90 \mathrm{~dB}$. Each subject received five trials of each of the six experimental conditions; for half of the trials involving prestimuli the tones were presented in the subject's left ear, and for the other half of the trials the tones were presented in the subject's right ear.

\section{Results and Discussion}

Figure 2 shows the mean amplitude, averaged across subjects, of eveblinks elicited in each of the five acoustic prestimulation conditions and in the no-prestimulation condition (horizontal line crossing the curve). Since there was no significant difference between responses when prestimuli were presented in the left ear vs. the right ear $(t=1.5$, df $=16$, $p>.10$ ), the means reported in the prestimulation conditions are averaged across lef $i$-ear trials and right-ear trials.

As can be seen from Figure 2, trials in which acoustic prestimuli were present yielded smaller reactions than trials in which only the reflex-eliciting stimulus was present and, in addition, the amount of inhibition appears to be an increasing function of prestimulus intensity. The reliability of these data is indicated by the result of a repeated-measures one-way analysis of variance which yielded: $F=18.41, \mathrm{df}=$ $4 / 68, p<.001$.

A Newman-Keuls test on individual comparisons of this data revealed a significant difference between the no-prestimulus condition and each of the prestimulus conditions ( $p<.05$ in each case). In addition, the 30-, 50-, and 70-dB prestimulus conditions were significantly different from the 90 -dB condition $(p<.05)$ but not significantly different from each other. In other words, this study has shown that the glabella reflex can be inhibited with acoustic prestimuli as low as $30 \mathrm{~dB}$ and that the amount of inhibition is an increasing function of prestimulus intensity.

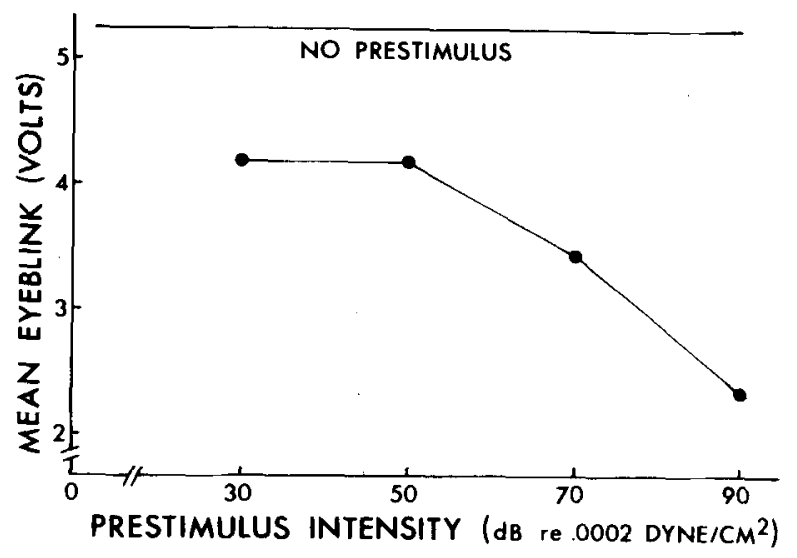

Figure 2. Mean eyeblink amplitude (across subjects) as a function of auditory prestimulus intensity for a stimulus configuration with a 100-msec interstimulus interval. The solid horizontral line above the curve represents the mean eyeblink amplitude for the noprestimulus configuration. 
Trends similar to the one observed here have been reported in studies using airpuffs (Marsh, Hoffman, \& Stitt, 1978) and loud, acoustic stimuli (Graham, $1975)$ as eyeblink-eliciting stimuli. Likewise, inhibition of the startle reflex of rats and pigeons is also a function of prestimulus intensity (Hoffman \& Wible, 1970; Ison \& Hammond, 1971; Stitt, Hoffman, Marsh, \& Schwartz, 1976). It appears to be a general principle of reflex modification that weak inhibition and stronger inhibitory stimuli produce larger amounts of inhibition.

\section{EXPERIMENT 3}

Experiment 3 sought to specify the relation between amount of inhibition and reflex-response amplitude as determined by the intensity of the reflex-eliciting stimulus.

\section{Method \\ Subjects. Sixteen (10 female, 6 male) undergraduate and grad- uate students from Bryn Mawr College participated in this exper- ment. \\ Procedure. All subjects were exposed to two basic stimulus patterns while viewing colored slides. One stimulus pattern con- sisted of a tap to the glabella (duration $50 \mathrm{msec}$ ) that had an intensity of $5,10,15,20$, or $25 \mathrm{~V} \mathrm{dc}$. The second pattern consisted of the same-intensity taps to the glabella presented $100 \mathrm{msec}$ after the onset of a $70-\mathrm{dB}$ prestimulus (duration, $50 \mathrm{msec}$; rise-decay time, $10 \mathrm{msec}$ ). Each subject received four trials of each of the 10 experimental conditions. As in the previous studies, for half of the trials involving prestimuli the tones were presented in the subject's left ear and for the other half of the trials tones were presented in the subject's right ear. Trial conditions were presented in random order with an intertrial interval of $20 \mathrm{sec}$.}

\section{Results and Discussion}

Figure 3 shows the mean amplitude, averaged across subjects, of eyeblink responses produced in each of the 10 experimental conditions. As in the previous experiments, the means reported in the prestimulation conditions are averaged across left-ear trials and right-ear trials because there was no significant difference between responses when prestimuli were presented in the left ear vs. the right ear (t $=.57, \mathrm{df}=14, \mathrm{p}>.10$ ).

A Treatment by Treatment by Subjects analysis of variance (Bruning \& Kintz, 1968) was used to evaluate the reliability of the observed trends. This test revealed a significant effect of reflex-eliciting stimulus intensity $(F=17.0, \mathrm{df}=4 / 60, \mathrm{p}<.001)-$ response amplitude increased with increased reflexstimulus intensity. This finding parallels the findings of Hoffman and Searle (1968), working with the rat's startle reflex, and of Marsh (1976), working with the human eyeblink response to airpuff stimuli. The analysis also revealed, as anticipated from the first two studies in the current report, a significant inhibitory effect of the acoustic prestimuli $(F=24.55$, df $=$ $3 / 12, \mathrm{p}<.001)$.

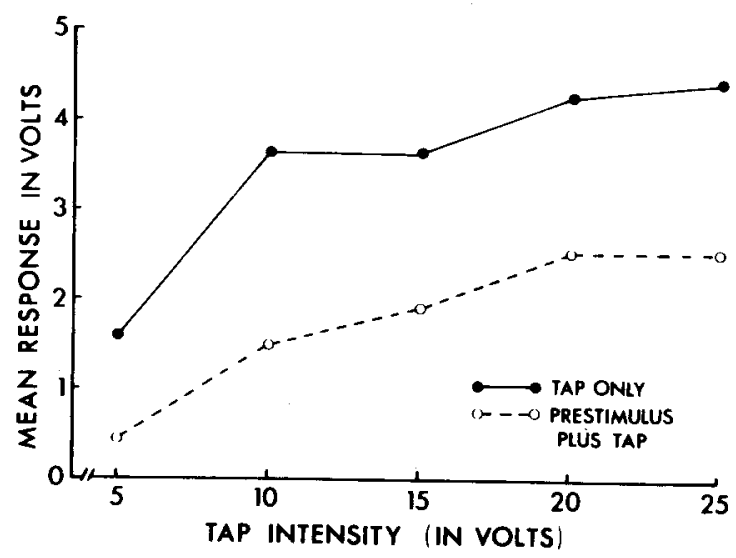

Figure 3. Mean eyeblink amplitude (across subjects) as a function of the intensity of the tap to the glabella. The solid curve indicates responses to those stimulus configurations consisting of only a tap to the glabella. The dashed curve indicates responses to those stimulus configurations in which a $7-\mathrm{dB}$ tone preceded the tap by 100 msec.

Finally, and most importantly, the data indicated no interaction between the reflex-eliciting stimulus intensity factor and the acoustic prestimulation factor $(F=.19, \mathrm{df}=3 / 12, \mathrm{n} . \mathrm{s}$.$) . The absence of a$ significant interaction term indicates that inhibition is a subtractive effect-an acoustic prestimulus with a 100-msec lead time reduces a glabella-reflex response by an amount that is independent of the intensity of the eliciting stimulus. This finding is in agreement with reports that inhibition is a subtractive process for both the startle reflex of the rat (Stitt, Hoffman, \& Marsh, 1976) and the airpuff-elicited eyeblink reflex of humans (Hoffman, Marsh, \& Stitt, in press), and suggests a second general principle of reflex modification: the inhibition effect is independent of the level of activity of the reflex mechanism as determined by reflex-eliciting stimulus intensity.

\section{EXPERIMENT 4}

This study was designed to evaluate the relative inhibitory effectiveness of monaural vs. binaural prestimulation. Marsh, Hoffman, and Stitt (1976) have reported that the human eyeblink reflex elicited by a puff of air is more strongly inhibited by monaural prestimulation than by binaural prestimulation. This finding was surprising, because numerous loudness matching experiments have shown that binaural acoustic signals are perceived to be slightly louder than the same signals presented monaurally (see Licklider, 1951) and, as previously discussed, investigations have always revealed that the inhibitory effect is an increasing function of the intensity of the inhibitory stimulus. Therefore, the present study was undertaken to determine if the Marsh et al. 
(1976) finding was peculiar to the airpuff-eliciting stimulus or if it also occurred when eyeblinks were elicited by taps to the glabella.

\section{Method}

Subjects. Ten (five female, five male) undergraduate and graduate students from Bryn Mawr College participated in this experiment.

Procedure. At the beginning of a session, each subject was given an alternating binaural loudness balance test. This test consisted of alternating between a $60-\mathrm{dB}$ sensation level (SL) tone in the ear with the lowest threshold (the more sensitive ear) and a tone of variable intensity in the less sensitive ear until the subject indicated that the variable tone was of equal loudness. On the basis of these measures, the intensities of the acoustic prestimuli employed in the experimental conditions described below were set at $60 \mathrm{~dB}$ SL for the more sensitive ear and at an equal loudness for the other ear.

During the experimental session itself, the subject viewed a sequence of color slides, during which he or she was exposed to each of four experimental stimulus configurations: a tap to the glabella preceded by a $1-\mathrm{kHz}$ acoustic prestimulus (1) to the left ear, (2) to the right ear, (3) to both ears in phase, or (4) no prestimulation. In those stimulus configurations that involved an acoustic prestimulus, the tone duration was $50 \mathrm{msec}$; its rise-decay time was $10 \mathrm{msec}$; and the interval between onset of the tone and the glabella tap was $100 \mathrm{msec}$. The tap to the glabella, in all stimulus configurations, was produced by delivering a $15-\mathrm{V} \mathrm{dc}$, 50 -msec pulse to the tap solenoid. Each subject received 10 trials of the four stimulus configurations. Configurations were presented in random order with an intertrial interval of $20 \mathrm{sec}$.

\section{Results and Discussion}

Observation of Figure 4, which shows the mean amplitude (averaged across subjects) of eyeblink responses produced in each of the four experimental conditions, reveals that both binaural and monaural prestimulation inhibits the glabella-reflex response. Furthermore, monaural prestimulation produces more inhibition than binaural prestimulation. These observations are confirmed by statistical analysis. A repeated-measures analysis of variance showed the acoustic prestimulus manipulation to have a significant effect $(F=73.32$, df $=3 / 27, p<.001)$. A Newman-Keuls test of individual comparisons showed no significant difference between prestimulation of the left ear alone and the right ear alone, although each of these conditions was significantly different from the binaural and no-prestimulation conditions ( $p<.01$ in each case). The binaural prestimulation condition, too, differed from the no-prestimulation condition $(p<.01)$.

The finding that the glabella reflex is inhibited almost twice as much by monaural prestimulation as by binaural prestimulation replicates almost exactly the finding of Marsh et al. (1976). Moveover, since the supremacy of monaural inhibiting stimuli has now been demonstrated using both airpuffs and glabella taps as eliciting stimuli, it is clear that this effect is not related to the eliciting stimulus.

At present, efforts at an explanation must be speculative, but it is reasonable to suppose that it is

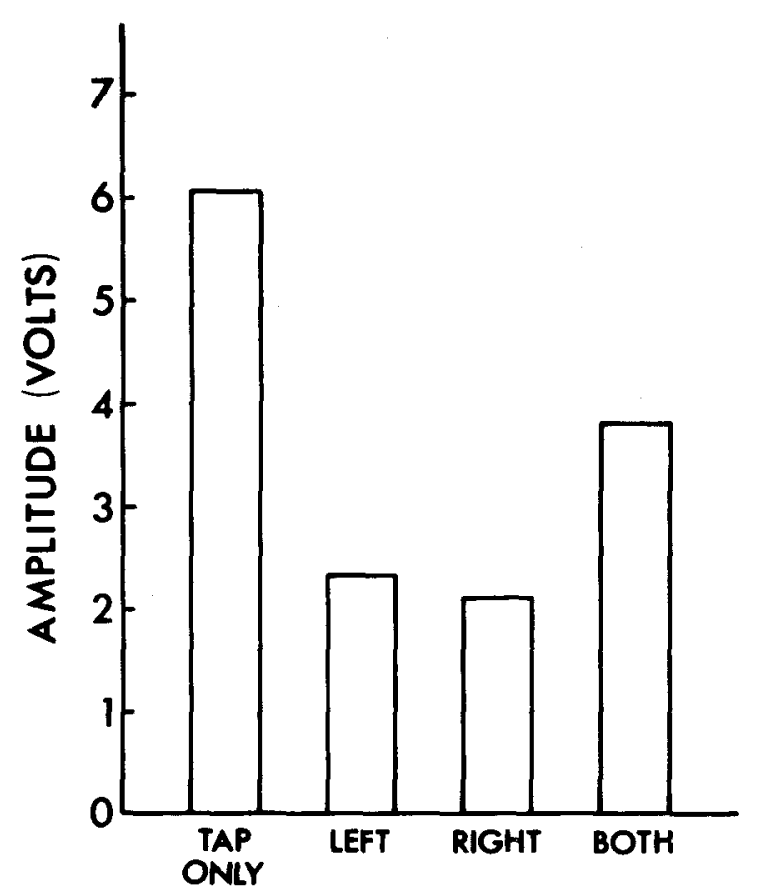

Figure 4. Mean eyeblink amplitude (across subjects) elicited by a tap to the glabella alone or a tap preceded by monaural or bingural prestimulation.

mediated by the neural pathways that pass from the cochlear neuclei to the lateral superior olives. These pathways are assumed to play an important role in auditory localization since they are arranged in such a way as to accentuate any differences in the intensities of the inputs to the two ears (Thompson, 1967). There are two kinds of such pathways: (1) an excitatory pathway from the cochlear neucleus on a given side to the lateral superior olive on the same side and (2) an inhibitory pathway from the cochlear neucleus on a given side to the lateral superior olive on the contralateral side. If the amount of reflex modification by an acoustic signal was determined by the combined excitatory output of the lateral superior olives (or by the output of a structure to which they project) and if the crossed inhibitory effects were large enough, input to only one ear might produce a larger total output from the lateral superior olives than would simultaneous (and mutually inhibitory) input to both ears.

\section{EXPERIMENT 5}

Experiment 5 was designed to determine if the termination of a steady acoustic signal could inhibit the eyeblink response of the glabella reflex. This reflex-modification effect (inhibition by offset of a sensory prestimulus) has previously been reported for the startle reflex of rats (Stitt, Hoffman, \& Marsh, 1973) and the acoustically elicited eyeblink reflex of 
humans (Zeigler \& Graham, 1979). A second purpose of this experiment was to extend our knowledge of monaural vs. binaural effects by determining if monaural termination of prestimulation produces more inhibition than binaural termination.

\section{Method}

Subjects. Ten (four female, six male) undergraduate and graduate students from Bryn Mawr College participated in this experiment.

Procedure. As described in Experiment 4, an alternating binaural loudness balance test was performed on each subject, and on the basis of this test the intensities of the acoustic stimuli were set at $60 \mathrm{~dB}$ SL for the more sensitive ear and at an equal loudness for the other ear. During the experimental session, the subject viewed a sequence of color slides and was exposed to each of five stimulus configurations: (1) a tap to the glabella (produced by a $50-\mathrm{msec}, 15-\mathrm{V}$ dc pulse to the tap solenoid) presented during continuously present binaural acoustic stimulation (frequency, $1 \mathrm{kHz}$; duration, $20 \mathrm{msec}$ ), (2) a tap to the glabella presented during continuously present monaural acoustic stimulation, (3) a tap to the glabella presented $100 \mathrm{msec}$ after the termination (decay time, $10 \mathrm{msec}$ ) of otherwise continuously present binaural acoustic stimulation, (4) a tap to the glabella presented $100 \mathrm{msec}$ after the termination of otherwise continuously present monaural acoustic stimulation, and (5) a tap to the glabella presented after a 20-sec interval of silence. Each subject received 10 trials of each of the five stimulus configurations. Half of the subjects received monaural stimulus configurations in the right ear, and half of the subjects received monaural stimulus configurations in the left ear. Stimulus configurations were presented in random order with an intertrial interval of $20 \mathrm{sec}$.

\section{Results and Discussion}

Figure 5 shows the mean amplitude, averaged across subjects, of eyeblinks elicited in each of the five

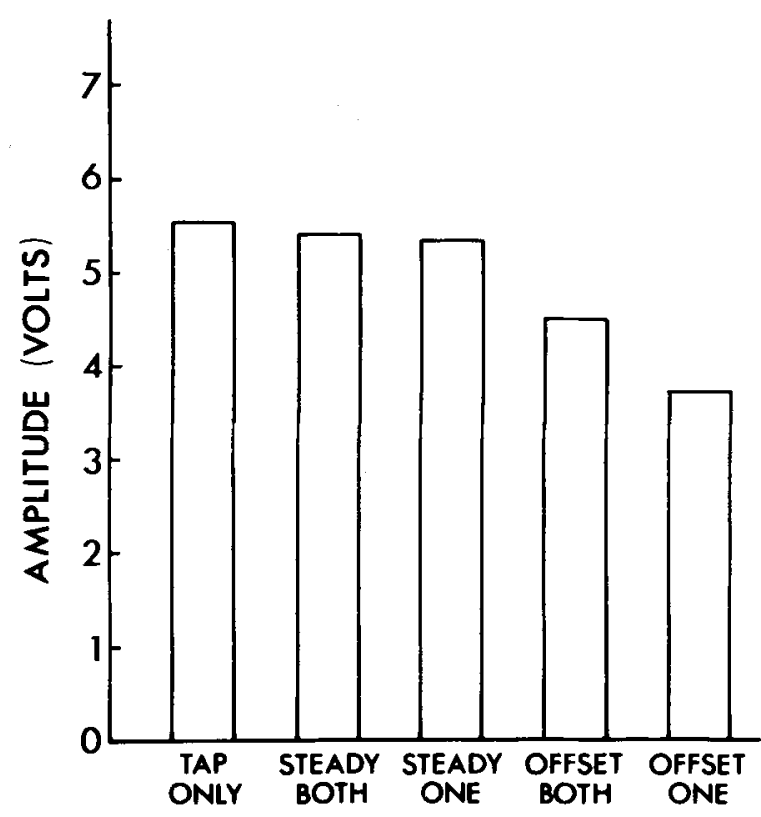

Figure 5. Mean eyeblink amplitude (across subjects) elicited by a tap alone in the presence of continuously present monaural or binaural stimulation, or a tap preceded by the offset of otherwise continuously present monaural or binaural prestimulation. experimental conditions. A repeated-measures analysis of variance revealed that the observed effects were statistically significant $(F=14.36, \mathrm{df}=4 / 36$, $p<.001)$. A Newman-Keuls analysis was then performed to test for individual differences. This analysis indicated no significant differences among the tap-only and the two steady-stimulation conditions (p > .05 in all cases). However, the monaural-offset and binaural-offset conditions were both different from the silent and steady-stimulation conditions. Furthermore, the monaural-offset condition was different from the binaural-offset condition $(p<.05$ in all cases).

The implications of Figure 5 are obvious; the offset of an otherwise continuously present acoustic signal inhibited the glabella reflex, and the offset of monaural acoustic stimulation produced more inhibition than did the offset of binaural acoustic stimulation. This represents a second entry in a potential list of monaural-binaural effects in reflex inhibition. It also implies that if, as suggested earlier, the lateral superior olives are the locus of the binaural vs. monaural effect, these structures must be sensitive to the offset characteristics of acoustic signals.

\section{CONCLUSIONS}

In general, the findings reported here are consistent with those of studies involving other organisms and forms of stimulation, though they extend them in several ways. They are consistent with earlier findings by revealing that inhibitory effects are detectable with reasonably weak signals $(30 \mathrm{~dB})$, by showing that the amount of inhibition is independent of the intensity of the reflex-eliciting stimulus, and by revealing that the binaural presentation of an acoustic signal produces less inhibition than the monaural presentation of the same signal. They extend the earlier findings by revealing that the offset of an acoustic signal presented monaurally also produces more inhibition than the offset of the same signal presented binaurally. As noted earlier, the reasons for this difference are at present still a subject for speculation. Even so, that the procedures used here should reveal a reliable difference is indicative of their sensitivity, and it implies that further work employing them should help to elaborate those reasons.

Overall, these experiments point to the efficacy of reflex modification as a tool in the analysis of sensory processes in man. Not only does it provide a sensitive technique for determining if a given sensory input has been processed, but it does so in an objective, quantitative fashion without requiring the direct cooperation of the subject. These factors seem adequate to recommend the use of reflex modification in comparisons of sensory processes across species and in certain difficult-to-test subjects, such as in- 
fants. There remains, however, the problem of fully describing the sensory mechanisms responsible for reflex modification and of accounting for their role in the organisms' reactions to events in the environment. Obviously, no single series of experiments is likely to resolve such complex issues. Still, by demonstrating that in man tap-elicited eyeblink is subject to reflex modification and by identifying certain of the parameters of the effect, the work reported here adds to the empirical base that will be needed for this effort.

\section{REFERENCE NOTE}

1. Ison, J. R. Personal communication, 1979.

\section{REFERENCES}

Bender, L. F., Maynard, A. B., \& Hastings, S. V. The blink reflex as a diagnostic procedure. Archives of Physical Medicine and Rehabilitation, 1969, 50, 27-39.

Bruning, J. L., \& Kin'rz, B. L. Computational handbook of statistics. Glenview, Ill: Scott, Foresman, 1968.

Buckland, G., Buckland, J., Jamieson, E., \& Ison, J. R. Inhibition of startle response to acoustic stimulation produced by visual prestimulation. Journal of Comparative \& Physiological Psychology, 1969, 67, 493-496.

Carhart, R., \& Jerger, J. Preferred method for clinical determination of pure-tone thresholds. Journal of Speech and Hearing Disorders, 1959, 24, 330.

Clay, S. A., \& RAmSeyer, J. C. The orbicularis oculi reflex in infancy and childhood. Neurology, 1976, 26, 521-524.

Cockburn, F., \& Drillen, C. (Ed.) Neonatal medicine. Oxford: Blackwell Scientific, 1974.

Granam, F. K. The more or less startling effects of weak stimulation. Psychophysiology, 1975, 12, 238-248.

Hoffman, H. S., Marsh, R. R., \& Stitt, C. L. Tests of a principle of reflex modification: Modification of the human eyeblink-reflex is independent of the intensity of the reflexeliciting stimulus. Animal Learning \& Behavior, in press.

Hoffman, H. S., \& SEarle, J. L. Acoustic and temporal factors in the evocation of startle. Journal of the Acoustical Society of America, 1968, 43, 269-282.

Hoffman, H. S., \& Wible, B. L. Role of weak signals in acoustic startle. Journal of the Acoustical Society of America, $1970,47,489-497$.

Ison, J. R., \& Hammond, G. R. Modification of the startle reflex in the rat by changes in the auditory and visual environments. Journal of Comparative and Physiological Psychology, $1971,75,435-452$.

KugE LBERG, E. Facial reflexes. Brain, 1952, 75, 385-396.

LICKLIDER, J. C. R. Basic correlates of the auditory stimulus. In S. S. Stevens (Ed.), Handbook of experimental psychology. New York: Wiley, 1951.
MARSH, R. Modification of the human eyeblink reflex by antecedent stimulation: Implications for objective audiometry. Unpublished doctoral disscrtation, Bryn Mawr College, 1976.

Marsh, R., Hoffman, H. S., \& StitT, C. L. Eyeblink inhibition by monaural and binaural stimulation: One ear is better than two. Science, 1976, 192, 390.

Marsh, R., Hoffman, H. S., \& Stitt, C. L. Reflex inhibition audiometry: A new objective technique. Acta Otolaryngologica, $1978,85,336-341$.

Marsh, R., Hoffman, H. S., \& StitT, C. L. Eyeblink elicitation and measurement in the human infant. Behavior Research Methods \& Instrumentation, 1979, 11, 498-502.

Overend, W. Preliminary note on a new cranial reflex. Lancet, $1896,1,619$.

Prechtl, H., \& Beintema, D. Neurological exam of the fullterm newborn infant. London: Spastics Society, Medical Education and Information Unit, 1964.

Reiter, L. A., \& Ison, J. R. Inhibition of the human eyeblink reflex: An evaluation of the sensitivity of the Wendt-Yerkes method for threshold detection. Journal of Experimental Psychology: Human Perception and Performance, 1977, 3, 325-336.

Schwartz, G. M., Hoffman, H. S., Stitt, C. L., \& Marsh, R. R. Modification of the rat's acoustic startle response by antecedent visual stimulation. Journal of Experimental Psychology: Animal Behavior Processes, 1976, 2, 28-37.

Shahani, B. T. The human blink reflex. Journal of Neurology, Neurosurgery, and Psychiatry, 1970, 33, 792-800.

Shahani, B. T., \& Young, R. R. Human orbicularis oculi reflexes. Neurology, 1972, 22, 149-154.

Shahan I, B. T., \& Young, R. R. Blink reflexes in orbicularis oculi. In J. E. Desmedt (Ed.), New developments in EMB and clinical neurophysiology (Vol. 3). Basel, Switzerland: S. Darger, 1973.

Stitt, C. L., Hoffman, H. S., \& Marsh, R. R. Modification of the rat's startle reaction by termination of antecedent acoustic signals. Journal of Comparative and Physiological Psychology, $1973,84,207-215$.

StitT, C. L., Hoffman, H. S., \& Marsh, R. R. Interaction versus independence of startle modification processes in the rat. Journal of Experimental Psychology: Animal Behavior Processes, 1976, 2, 260-265.

StitT, C. L., Hoffman, H. S., Marsh, R. R., \& Schwartz, G. M. Modification of the pigeon's visual startle reaction by the sensory environment. Journal of Comparative and Physiological Psychology, 1976, 90, 601-619.

Thompson, R. F. Foundations of physiological psychology. New York: Harper and Row, 1967.

Zeigler, B. L., \& Graham, F. K. Developmental differences in processing of transient and sustained stimulation. Psychophysiology, 1979, 16, 177.

(Received for publication April 3, 1979; revision accepted October $27,1979$. 